Paedagogia Christiana

I/29 (2012) - ISSN 1505-6872

Stanistawa Konefat*

Lublin

\title{
Pedagogiczna wielowymiarowość rozwoju. Jednostka - przestrzeń społeczna - instytucja, Lublin, 4-6 kwietnia 2011 roku
}

W dniach 4-6 kwietnia 2011 roku odbyła się w Katolickim Uniwersytecie Lubelskim Jana Pawła II międzynarodowa konferencja naukowa z okazji 30-lecia reaktywacji Instytutu Pedagogiki. Hasłem tych jubileuszowych, naukowych obrad była: pedagogiczna wielowymiarowość rozwoju w aspekcie samej jednostki, przestrzeni społecznej i instytucji. Ranga konferencji była tym większa, że odbyła się ona z udziałem abpa Celestino Migliore, Nuncjusza Apostolskiego w Polsce. Patronat nad konferencją objął kard. Zenon Grocholewski, Prefekt Kongregacji Wychowania Chrześcijańskiego, oraz prof. dr hab. Barbar Kudrycka, Minister Nauki i Szkolnictwa Wyższego. Komitet Naukowy stanowili profesorowie: Mieczysław Adamczyk, Franciszek Adamski, Wiesław Ambrozik, ks. Jerzy Bagrowicz, Józef Górniewicz, Teresa Hejnicka-Bezwińska, Krystyna Chałas, Maria Dudzikowa, Jadwiga Izdebska, Grażyna Karolewicz, Janusz Kirenko, Stanislav Košč, Jadwiga Kuczyńska-Kwapisz, Teresa Kukołowicz, Stefan Kwiatkowski, Zbigniew Kwieciński, Tadeusz Lewowicki, o. Zbigniew Marek, ks. Janusz Mastalski, Zbyszko Melosik, Zofia Matulka, Edward Mazurkiewicz, Aleksander Nalaskowski, Jerzy Jan Niemiec, Jerzy Nikitorowicz, ks. Marian Nowak, Katarzyna Olbrycht, Zofia Ostrihanska, Stanisław Palka, Kazimierz Przyszczypkowski, Marian Surdacki, Mirosław J. Szymański, Mirosław S. Szymański,

* Mgr Stanisława Konefał - doktorantka w Katedrze Pedagogiki Chrześcijańskiej, w Instytucie Pedagogiki Katolickiego Uniwersytetu Lubelskiego Jana Pawła II. 
Tomasz Szkudlarek, Bogusław Śliwerski, ks. Janusz Tarnowski, ks. Edward Walewander.

Motywem organizacji przedsięwzięcia była trzydziesta rocznica reaktywacji Instytutu Pedagogiki w Katolickim Uniwersytecie Lubelskim. Celem konferencji było ukazanie dominujących tendencji w tworzeniu wiedzy pedagogicznej; upowszechnianie aktualnych wyników badań pedagogicznych i doświadczeń środowisk naukowych w zakresie pedagogicznej wielowymiarowości rozwoju. Podejmowano także dyskusję nad perspektywami rozwoju teorii i praktyki edukacyjnej, której celem szczegółowym miało być poszukiwanie pedagogicznej odpowiedzi na wyzwania zmieniającej się rzeczywistości, a efektem typowo praktycznym - powołanie „Forum pedagogów teoretyków i praktyków integralnego rozwoju i wychowania”. W konferencji wzięło udział ponad 140 prelegentów. Wśród zaproszonych gości znaleźli się zagraniczni naukowcy, między innymi prof. Stanislav Košč, prof. Frantisek Drozd, prof. dr med. Thomas Hülshoff z Katholische Hohschule Nordrhein-Westfalen w Niemczech.

Konferencja odbywała się w Kampusie Akademickim Katolickiego Uniwersytetu Lubelskiego Jana Pawła II przy ulicy Droga Męczenników Majdanka $70 \mathrm{w}$ Lublinie. Tematyka obrad podejmowana była w referatach plenarnych i sekcyjnych, połączonych z dyskusją. Ze względu na liczny udział czynnych uczestników tego naukowego przedsięwzięcia zostało ono podzielone na dziewięć sekcji tematycznych.

Pierwszy dzień spotkania konferencyjnego miał charakter typowo odświętny, naukowo-jubileuszowy. Uroczystej inauguracji dokonano podczas Eucharystii w nowo poświęconej kaplicy na terenie jednego z obiektów kampusu. Msza Święta sprawowana pod przewodnictwem Nuncjusza Apostolskiego w Polsce, abpa Celestino Milgiore, w asyście JM Rektora KUL, ks. prof. dra hab. Stanisława Wilka i JE ks. bpa Mieczysława Cisło oraz licznie zebranych kapłanów, była doskonalą okazją do dziękczynienia Bogu za fenomen kulowskiej pedagogiki oraz wyrazem prośby społeczności akademickiej i wszystkich gości o dalszy rozwój a także pomyślność tego dzieła. Po wspólnej modlitwie nastąpiło uroczyste rozpoczęcie konferencji. Kolejno dokonali go JM ks. prof. dr hab. Stanisław Wilk, JE ks. bp. Mieczysław Cisło, JE ks. abp Celestino Milgiore, dziekan Wydziału Nauk Społecznych, prof. dr hab. Andrzej Sękowski, mgr Krzysztof Babisz, Lubelski Kurator Oświaty. Zaproszonych gości i uczestników konferencji powitała również dr hab. Alina Rynio, prof. KUL - dyrektor Instytutu Pedagogiki.

Następnie odbyła się sesja plenarna z trzema przerwami, której przewodniczyli ks. prof. Edward Walewander, prof. Wanda Dróżka, ks. prof. Marian Nowak. W pierwszej części obrad plenarnych ks. prof. Marian Nowak wprowadził wszystkich uczestników w specyfikę pedagogiki i jej tożsamość. 
Prof. Stanisław Palka ukierunkował myślenie słuchaczy na istniejące zróżnicowanie w metodologii badań pedagogicznych dotyczących wielowymiarowości rozwoju człowieka. Po przerwie obiadowej i prezentacji materiałów edukacyjnych firmy Nowa Szkoła, głos zabrał ks. prof. Zenon Uchnast. Wygłosił on referat na temat integralnego rozwoju człowieka w podejściu synergetycznym. Nad wychowaniem w warunkach wielokulturowości i jego wyzwaniami, między innymi wspieraniem rozwoju tożsamości wielowymiarowej, rozprawiał kolejny z prelegentów, prof. Jerzy Nikitorowicz. W ostatniej części sesji plenarnej podczas pierwszego dnia konferencji prof. Krystyna Duraj-Nowakowa omówiła tendencje w tworzeniu wiedzy pedagogicznej a prof. Wanda Dróżka, opierając się na autobiografiach i pamiętnikach rożnych pokoleń nauczycieli, uświadomiła słuchaczom, iż istnieje potrzeba integracji osobowości, wiedzy i doświadczenia w kształceniu i rozwoju zawodowym nauczycieli. Przedstawione wystąpienia można było poddać dyskusji w czasie otwartego mikrofonu, który poprowadził ks. prof. Marian Nowak.

Całość naukowych rozważań w pierwszym dniu międzynarodowej konferencji uwieńczył jubileuszowy bankiet. Była to doskonała okazja do wspólnotowego odpoczynku, wymiany naukowych myśli i doświadczeń oraz chwil refleksji przy akompaniamencie muzyki.

Obrady w grupach sekcyjnych wypełniły popołudniową część drugiego dnia konferencji. Wprowadzenie do nich stanowiły dwie sesje plenarne a następnie prezentacja materiałów edukacyjnych firmy Moje Bambino. Nadmienić należy, że przed południem miało również miejsce otwarcie sesji plakatowej, ukazującej w sposób plastyczny i nowatorski, a przy tym cenny merytorycznie, pedagogiczną wielowymiarowość rozwoju. Wtorkowa, dwuczęściowa sesja plenarna poświęcona została: integralnemu rozwojowi człowieka jako podstawie wychowania w nauczaniu społecznym Kościoła, którą zaprezentował prof. Stanislav Košč. Następnie ks. prof. Mieczysław Rusiecki scharakteryzował proces wychowania religijnego w rodzinie, a prof. Ryszard Bera ukazał emigrację zarobkowa jako nowy obszar badawczy pedagogiki pracy. Pod przewodnictwem prof. Kazimiery Krakowiak w drugiej części obrad plenarnych debatowano także nad szkołą wobec edukacyjnych intencji z uczestnictwem prelegenta prof. Jerzego Niemca. Na zakończenie dr Teresa Chmiel starała się dotrzeć do źródła przyczyny sprawczej, jaką jest według prelegentki awersja do matematyki, stojącej u podstaw studiowania pedagogiki przez studentów tego kierunku.

Popołudniowe spotkania sekcyjne $\mathrm{w}$ tym dniu oraz równoległe im tematycznie a mające miejsce podczas ostatniego dnia konferencji, przebiegały w dziewięciu grupach skoncentrowanych wokół różnorodnych obszarów tematycznych: 
Sekcja I - ,Wczoraj” $i$,dziś" pedagogiki jako nauki osoby

Sekcja II - Antropologiczno-etyczne konteksty urzeczywistniania się

Sekcja III - Religijno-moralne wymiary rozwoju i wychowania

Sekcja IV - Integralny rozwój osoby a wychowanie

Sekcja V - Pedagogiczna wielowymiarowość rozwoju wobec rzeczywistości rodziny

Sekcja VI - Szkoła w integralnym rozwoju ucznia i nauczyciela - stan faktyczny i postulowany

Sekcja VII - Środowisko społeczne miejscem rozwoju

Sekcja VIII - Urzeczywistnianie się osoby z niepetnosprawnościa

Sekcja IX - Wychowanie w kontekście współczesnych przemian kulturowych.

W sekcji I prowadzącym był prof. Marian Surdacki. Referenci zaprezentowali następujące tematy: ks. prof. Janusz Mastalski: Istota pedagogiki chrześcijańskiej, prof. Grażyna Karolewicz: Ze wspomnień pedagoga, prof. Ryszard Skrzyniarz: Obraz prof. Stefana Kunowskiego we wspomnieniach studentów, ks. prof. Edward Walewander: Pedagogia życia prof. Mieczystawa Wieliczki (1935-2009), dr Ryszard Małachowski: Męczeństwo jako kategoria wychowania na przykładzie sióstr nazaretanek z Nowogródka oraz księdza Aleksandra Zienkiewicza (lata 1943-1946), mgr Elżbieta Krzewska: Ideaty wychowania i wzorce osobowe twórczości Antoniego Józefa Rollego, dr Katarzyna Braun: Pedagogika chrześcijańska na KUL. Źródła i kierunki rozwoju, mgr Zdzisława Krzyżanowska: Filary nauczycielstwa w Bogorii w latach 30. i 40. XX wieku, dr Renata Bednarz-Grzybek: Wokót pedagogiki na tamach „Bluszczu”, dr Piotr Magier: Pedagogika ogólna w strukturze nauk pedagogicznych, ks. dr Leszek Waga: Analiza porównawcza podstaw metodologicznych pedagogiki i pracy socjalnej.

Przedmiotem dyskusji w grupie drugiej były antropologiczno-etyczne konteksty urzeczywistnia się osoby. Prowadzącym obrady był prof. Grzegorz Grzybek. W grupie zaprezentowano następujące referaty: dr Barbara Kiereś: Od wiedzy o człowieku do sztuki wychowania, dr Witold Starnawski: Unikalność - jej konsekwencje dla poznania i rozwoju osoby, dr Iwona Jazukiewicz: Cnota jako kategoria urzeczywistniania się osób w wychowaniu, dr Jarosław Horowski: Urabianie a inicjacja w procesie wychowania, ks. dr Andrzej Łuczyński: Autorytet i odpowiedzialność w wychowaniu, dr Katarzyna Stępień: Rozwój dziecka w kontekście wspótczesnej ochrony praw dziecka, prof. Grzegorz Grzybek, mgr Sławomir Baran: „Etyka rozwoju” a ojcostwo. Aspekty wychowania w rodzinie, dr Arkadiusz Wąsiński: Integralne ujęcie wychowania $w$ świetle autokreacyjnego wzrastania do rodzicielstwa zastepczego. 
Temat, nad którym pracowano w trzeciej sekcji, brzmiał: Religijno-moralne wymiary rozwoju $i$ wychowania. Obradom tej sekcji przewodniczył prof. Ryszard Polak. Tematy referatów sekcji trzeciej przedstawiają się następująco: prof. Lucyna Dziaczkowska: Religijno-moralny wymiar rozwoju $i$ wychowania człowieka. Potrzeby i zagrożenia, ks. prof. Jerzy Kułaczkowski: Zasady wychowania dziecka w rodzinie w świetle Biblii, dr Monika Hajkowska: Wychowanie religijno-moralne $w$ rodzinie polskiej $w$ XIX wieku, ks. dr Czesław Galek: Wychowanie religijne młodzieży szkolnej w II połowie XIX wieku w świetle polskiej literatury pamiętnikarskiej i beletrystycznej, s. dr Maria Opiela: Koncepcja pedagogiczna bt. Edmunda Bojanowskiego, prof. Ryszard Polak: Wychowanie religijne czlowieka w ujęciu ks. Józefa Winkowskiego, prof. Alina Rynio: Pedagogiczne przestanie Jana Pawła II podstawa i gwarantem tożsamości pedagogiki chrześcijańskiej, o. dr Roman Jusiak: Wychowanie społeczne w nauczaniu papieża Jana Pawła II, mgr Dorota Frąk: Rola środowisk wychowujących na przyktadzie instytucji wychowawczych prowadzonych przez Zgromadzenie Stug Jezusa, dr Marcin Białas: Podstawy wychowania chrześcijańskiego w aspekcie szczęścia i cierpienia, mgr Stanisława Konefał: Miejsce i rola przyjaźni w wychowaniu chrześcijańskim, dr Lidia Dakowicz: Wartości religijne w przekazie nauczycieli wybranych szkót w Białymstoku.

Czwarta grupa dyskusyjna, której obradom przewodniczył prof. Wiesław Wójcik, podjęła temat: Integralny rozwój osoby a wychowanie. Przedstawiono dziewięć zaplanowanych referatów. Grupę refujących stanowiły osoby związane z rożnymi ośrodkami naukowymi krajowymi i zagranicznymi. Tematy referatów przedstawiają się następująco: prof. Wiesław Wójcik: Budowa modelu integralnego rozwoju człowieka w oparciu o filozofie dialogu, dr Stanisław Michałowski: Na spotkanie człowieka. Edukacja integralna w paradygmacie personologicznym, dr Agata Celińska-Miszczuk: Rozwój osoby w ujęciu W. Sterna, dr Anna Lendzion: Transgresja i autotranscendencja w aspekcie rozwoju i wychowania, prof. Frantisek Drozd: Znaczenie doradztwa dla integralnego rozwoju osoby, dr Klemens Płeczkan: Jakość życia człowieka starego - oczekiwania a rzeczywistość, dr Zbigniew Rudnicki: Umieranie i śmierć w perspektywie pedagogicznej, dr Ewelina Świdrak: Opieka nad wnukami szansa rozwoju dziadków, mgr Marlena Wilgocka: Teatr jako czynnik integralnego rozwoju dziecka.

Tytuł organizujący wystąpienia uczestników V sekcji brzmiał: Pedagogiczna wielowymiarowość rozwoju wobec rzeczywistości rodziny. Obradom w sekcji V przewodniczyły: dr Danuta Opozda i dr Beata Wołosiuk. W grupie zaprezentowano dużą ilość referatów, dlatego jej obrady podzielono na dwa dni trwania konferencji. Kolejno swoje wystąpienia zaprezentowali: ks. mgr Marek Jeziorański: Filozoficzne podstawy rozwoju matżonków w nauczaniu 
Jana Pawła II, dr Andrzej Mazan: Metody integracji osoby w wychowaniu rodzinnym, ks. dr Jacek Łukaszewicz, dr Marta Pawelec: Kryzys wartości w kontekście etapów życia rodzinnego, dr Danuta Opozda: Funkcja regulacyjna systemów wartości w konstruowaniu jednostkowej wiedzy o wychowaniu, dr Beata Wołosiuk: Komunikacja interpersonalna w rodzinie w kontekście wychowania do wartości, mgr Mirosław Hanulewicz: Przygotowanie matżonków do narodzin dziecka szansa ich rozwoju, dr Renta Kowal: Medialny obraz wspótczesnej rodziny - przeniesienie „obrazu” do rzeczywistości, mgr Małgorzata Dorota: Specyfika etapu rodziny z matymi dziećmi $w$ aspekcie treści blogów internetowych pisanych przez matki, mgr Lydmyla Smygur: Postrzeganie rodzin wielodzietnych przez młodzież studiująca w Polsce i na Ukrainie. Raport z badań, dr Magdalena Pakuła: Alternatywy wobec matzeństwa i rodziny w percepcji mlodych doroslych, dr Agnieszka Regulska: Wspótczesne wyzwania wobec organizacji i funkcjonowania rodzin zasteppzych, dr Anna Dudak: Opieka naprzemienna jako nowa forma funkcjonowania rodziny po rozwodzie, mgr Anna Graboś-Złotek: Samotność i osamotnienie dzieci w rodzinach rozbitych i migracyjnych, dr Tomasz Wach: Jakość wychowania rodzinnego a udziat nieletnich sprawców czynów zabronionych $w$ podkulturze nieformalnej.

VI grupa sekcyjna obradowała wokół tematyki: Szkoła w integralnym rozwoju ucznia i nauczyciela - stan faktyczny i postulowany. Prelegenci wygłaszali swoje referaty w drugim i trzecim dniu konferencji. Prowadzącymi obrady były: prof. Krystyna Chałas i prof. Ewa Skrzetuska. Tytuły referatów wieloaspektowo podejmowały temat główny a brzmiały one następująco: prof. Krystyna Chałas i dr Beata Komorowska: Wybrane teorie szkoty $i$ ich implikacje dla praktyki edukacyjnej, dr Anna Popławska: Szanse i zagrożenia rozwoju podmiotowości w szkole, mgr Mariola Pałka-Pilecka: Osobowe relacje podmiotów szkoły, dr Katarzyna Kochan: Edukacja wczesnoszkolna po reformie - stan postulowany i rzeczywisty, dr Joanna Karczewska: Wychowanie dzieci przedszkolnych $w$ świetle koncepcji Stefana Kunowskiego, dr Iwona Zwierzchowska: Niepubliczna edukacja przedszkolna wobec wyzwań zmieniającej się rzeczywistości, dr Krystyna Kusiak, dr Beata Bednarczuk, dr Dorota Zdybel: Nauczyciel europejski czyli jaki? Wymiary rozwoju profesjonalnego wspótczesnych nauczycieli, mgr Monika BaryłaMatejczuk: Profesjonalne doskonalenie nauczycieli jako jeden z warunków skuteczności działań w środowisku szkolnym, dr Katarzyna Palka: Możliwości wyrównywania szans edukacyjnych $w$ szkole wiejskiej, prof. Wojciech Jan Maliszewski: Blaski i cienie kształcenia kompetentnego nauczyciela, $\mathrm{dr}$ Ewa Jakubiak-Zapalska: Rola nauczyciela we wspieraniu ucznia zdolnego we wspótczesnej szkole, ks. prof. Adam Maj: Wielowymiarowość źródet teorii i pedagogii szkoty - na przykładzie szkoty katolickiej, dr Anita Famuła- 
Jurczak: Gimnazjum miejscem rozwoju uczniów czy obszarem bezradności pedagogicznej, mgr Ewa Staropiętka-Kuna, mgr Elżbieta Miterka: Metoda projektów jako czynnik integralnego wychowania, dr Jadwiga Daszykowska: Rola szkoły w kreowaniu jakości życia dziecka, dr Barbara Wolny: Szkolna edukacja zdrowotna w przygotowaniu uczniów do jakości życia związanej ze zdrowiem, dr Zbigniew Ostrach: Kształcenie ekologiczne na różnych etapach nauczania, dr Roman Gawrych: Strategie motywowania uczniów do nauki we współczesnej szkole, dr Lilianna Kostańska: Środowisko wychowawcze a percepcja szkoty wśród uczniów kończacych szkołe podstawową.

Uczestnicy kolejnej sekcji VII rozważali temat: Środowisko społeczne miejscem rozwoju. Referenci pod przewodnictwem prof. Wiesława Wójcika, prof. Krystyny Duraj-Nowakowej i mgr Stanisławy Konefał przedstawili następujące zagadnienia: prof. Wiesław Wójcik: Budowa modelu integralnego rozwoju człowieka w oparciu o filozofie dialogu, dr Stanisław Michałowski: Na spotkanie człowieka. Edukacja integralna w paradygmacie personologicznym, dr Beata Jakimiuk: Kariera zawodowa i jej uwarunkowania w kontekście edukacji permanentnej, dr Tomasz Cuber: Kształtowanie poczucia odpowiedzialności wśród studentów na kierunku pielegniarstwo, referat przygotowany przez następujące osoby: prof. Irena Wrońska, dr Tomasz $\mathrm{Cu}$ ber, dr Zofia Kostrzanowska, mgr Aneta Kościołek, ks. dr Waldemar Klinkosz: Motywacja osiagnięć studentów a poziom lęku i zadowolenie z życia, dr Justyna Iskra: Wychowawcze uwarunkowania prężnego funkcjonowania a obraz siebie. Badania młodzieży rozpoczynającej studia, prof. Elżbieta Gaweł-Luty: Klasa szkolna jako miejsce społecznego rozwoju ucznia, dr Marianna Powałka: Przedstawiciele społeczności lokalnej wobec problemów dziecka i rodziny na swoim terenie, dr Anna Kanios: Wspótpraca organizacji pozarzadowych z sektorem samorzadowym na rzecz przeciwdziałania wykluczeniu społecznemu młodzieży, mgr Ewa Sosnowska-Bielicz: Szkoły niepubliczne - rozważanie za i przeciw, mgr Olga Krasuska: Uczeń z Kaukazu $w$ polskiej szkole i jego relacje społeczne.

Sekcja VIII poprowadzona została przez dr Ewę Domagała-Zyśk i skoncentrowała się wokół tematu: Urzeczywistnianie się osoby z niepetnosprawnościa. Kolejno swoje referaty zaprezentowali: dr Stanisława Byra, dr Monika Parchomiuk: Niepetnosprawność osób ze środowiska akademickiego $w$ percepcji niepetnosprawnych studentów, dr Beata Szabała: Samoocena a kompetencje społeczne studentów z niepełnosprawnościa sensoryczna, dr Ewa Domagała-Zyśk: Nauczanie języka obcego uczniów niesłyszacych jako przekraczanie barier w rozwoju językowym, dr Bożena Sidor-Piekarska: Wczesna interwencja jako proces wspierania dziecka zagrożonego niepetnosprawnościa i jego rodziców, dr Urszula Klajmon-Lech: „, Razem możemy więcej" - znaczenie stowarzyszeń w integrowaniu rodzin osób z niepetno- 
sprawnościa, mgr Małgorzata Zawadzka: Wsparcie rodziców dziecka z wieloraka niepetnosprawnościa $w$ trakcie wczesnego wspomagania rozwoju, mgr Monika Skop: Niepetnosprawność - walka o codzienność, prof. Thomas Hülshoff: When the elderly disabled become ill - A New challenge for pedagogues.

Ostatnia sekcja IX zajmowała się wychowaniem w kontekście współczesnych przemian kulturowych. Przewodniczył jej ks. dr Jerzy Król, który wystąpił z referatem: Edukacja w dobie globalizacji. Inni prelegenci przedstawili tematy: dr Wanda Wawro: Wybrane aspekty socjalizacji mtodzieży w społeczeństwie ryzyka, dr Dorota Bis: Media w życiu społecznym, $\mathrm{dr}$ Małgorzata Centner-Guz: Udziat telewizji w budzeniu negatywnych emocji u dzieci w wieku przedszkolnym, mgr Grzegorz Wołoszyn: Interaktywne kursy multimedialne oraz multimedialne nagrania wykładów jako dwie kluczowe formy nauczania zdalnego w szkołach wyższych, dr Ewa Smołka: Piękno w wychowaniu, dr Anna Dąbrowska: Aktywność kulturalna a językowy obraz świata młodzieży, dr Mariola Kozubek: Dialog katolicko-muzułmańskipropozycja pedagogii jedności, mgr Piotr Zańko: Obrazoburstwo czy pedagogika? Religia w wytworach wizualnych polskich prowokatorów kultury, $\mathrm{dr}$ Marcin Szewczak, mgr Iwona Szewczak: Rola administracji samorzadowej w rozwoju edukacji na rzecz dialogu wielokulturowego pogranicza polskoukraińskiego, mgr Justyna Palacz: Nowe formy wykorzystywania czasu wolnego wspótczesnej młodzieży, dr Krzysztof Przybycień: Autokreacja jako cel działalności w perspektywie przemian cywilizacyjnych i kulturowych.

Nadmienić należy, że drugi dzień konferencji po przedstawieniu komunikatów z obrad w sekcjach, uwieńczył koncert Orkiestry Barokowej Ogólnokształcącej Szkoły Muzycznej I i II st. im. K. Lipińskiego w Lublinie.

Po odczytaniu sprawozdań z pracy grup sekcyjnych podsumowania konferencji dokonała prof. Alina Rynio. Jeszcze raz przywołała historię pedagogiki w KUL oraz jubileuszowe okoliczności zorganizowania tego kończącego się międzynarodowego naukowego przedsięwzięcia. Zauważono także potrzebę debaty nad obliczem współczesnej pedagogiki w kontekście zróżnicowanej wielowymiarowości rozwoju jednostki, przestrzeni społecznej i instytucji. 